\title{
Recuperación de pinturas murales en la iglesia del monasterio de San Pedro de Cardeña (Burgos). Policromía: ornamento y simbolismo
}

Concepción Bengoechea Agustino * y Pedro Hombria Maté *

\section{RESUMEN}

A través de las pinturas murales

recuperadas en la capilla de los Mártires del Monasterio Benedictino de Cardeña, se hace una aproximación a la iconografía y el simbolismo de los colores y las formas. Los elementos arquitectónicos se transforman, por medio de la policromia en volúmenes escultóricos con significado propio.

\section{ABSTRACT}

Throughout the wall paintings recovered at the Chapel of the Martyrs in the Benedictine Monastery of Cardeña, an approach is held to the iconography and symbolism of colours and shapes. The architectural items are changed by polychrome into sculptural volumes with a meaningful significance.

\section{EL MONASTERIO}

Situado a unos once kilómetros de la ciudad de Burgos, el Monasterio de San Pedro de Cardeña es un punto de visita obligada. No defraudará a quien siga el consejo, porque a su indudable interés histórico y artístico une la belleza del paraje en que se ubica, la amenidad del trayecto, que abarca en su camino el parque de Fuentes Blancas, pulmón de la ciudad, y la Cartuja de Santa María de Miraflores.

Como todo monumento, el conjunto monástico, declarado en la temprana fecha de 1931, enseña al lector avisado las huellas de su historia, tanto con

* Restauradora.

** Arquitecto 


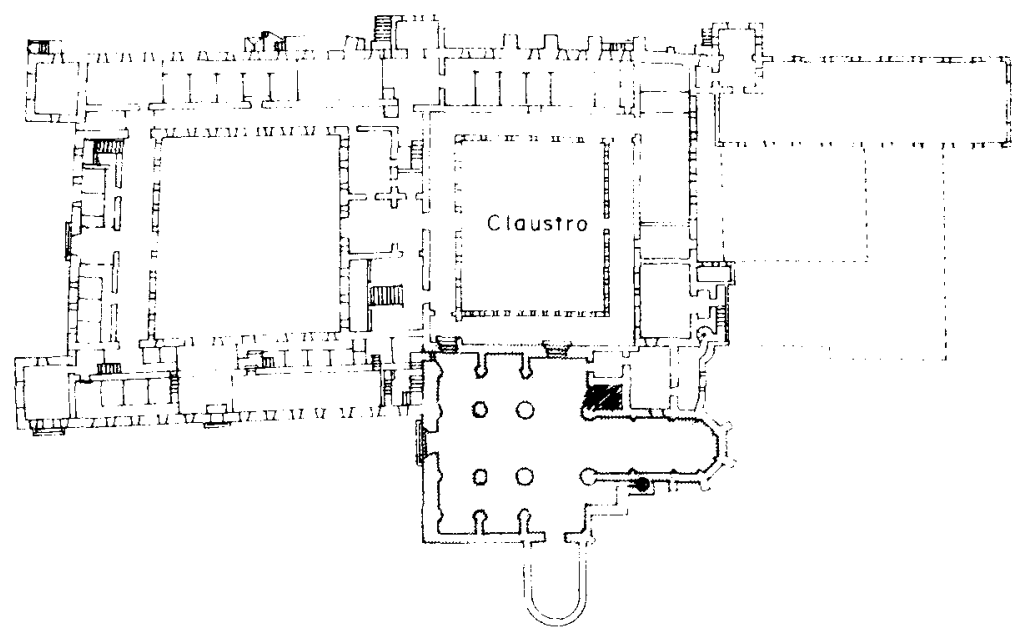

Capilla de los Mártires. Planta General del Monasterio.

presencias como con ausencias. $Y$ en primer lugar, con su asentamiento; hasta tres interpretaciones se barajan para el topónimo cardeña ', pero la vista termina dando la razón a la que apunta al color de la vegetación.

La primera fundación, muy debatida por los estudiosos, a caballo entre la Historia y la Leyenda, se ha querido remontar al siglo vi, pero sin fundamento. El documento histórico más antiguo en el que se hace referencia

Para el topónimo cardeña se han barajado tres explicaciones: La más audaz dice que es un compuesto de origen ibero y alude a esa altura (kara) y a su condicion de promontorio sacro (denia = sagrada, traducida al latín por digna y ambos juntos, karadigna), es decir, altura o promontorio sagrado. El mismo elemento kara se encuentra en Carcedo (caraceto) y Carrasca (carasca, con diminutivo ibero en -sca), hoy el Carrascal.

La más comúnmente aceptada hace referencia al color de la flor del cardo: "Del latín tardio cardinus = azulado, derivado de carduus $=$ cardo, por el color de las flores de esta planta. En el siglo x, los mozárabes llamaban qardenyella, por el adjetivo romance cárdeno o azul verdoso, a la anagálida azul o hierba pajera, a la que se atribuyeron antiguamente numerosas virtudes analgésicas y contra las inflamaciones. úlceras, manchas de la piel e incluso mordeduras de animales ponzoñosos." Pancracio CELDRAN, "Diccionario de topónimos españoles y sus gentilicios» Espasa Calpe, Madrid. 2002, págs. 214 y 215

Por último, como recoge Rodrigo AMADOR DE l.os Rios en un libro de referencia obligada ("España. Sus Monumentos y Artes. Su naturaleza e Historia. Burgos", Barcelona, 1888), el término puede proceder del árabe "Gar-ad-dina", "refugio de nuestra ley".

Nos inclinamos por la segunda. La primera ignora o contradice la sencilla correspondencia de Carrascal con el carrasco o encina pequeña; la tercera. parece demasiado complicada frente a la simplicidad de la favorita y presupone además que el lugar estaba innominado antes de la "razzia" de Abderramán III 


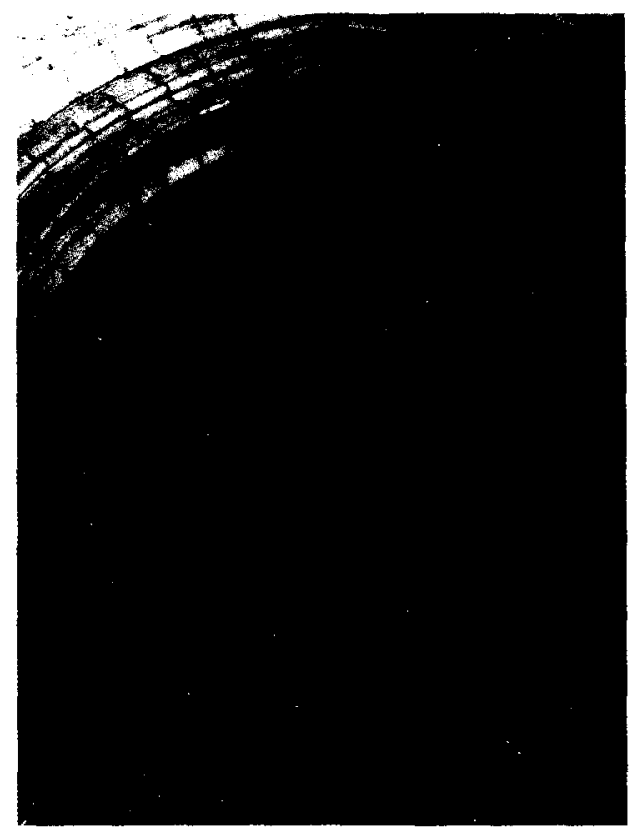

Capilla de los Mártires en San Pedro de Cardeña una vez concluida su restauración.

a Cardeña dice que el rey Alfonso de León "pobló" (es decir, que repobló) Cardeña en el 899 , lo que significa que para esta fecha ya estaba activo. Más tarde, en el $934^{2}$, se produce, al parecer, la multitudinaria matanza de monjes en el curso de una razzia atribuida a Abderramán III y que explica la advocación actual; Santa María de los Santos Mártires de Cardeña, que convive con la más conocida, y antigua, de San Pedro de Cardeña. Nos detendremos más en aquella, ya que las pinturas murales de cuya recuperación damos noticia se encuentran precisamente en la Capilla de los Mártires, en la cabecera de la nave del Evangelio. Sigamos, sin embargo, con la Historia.

La crónica medieval, transcrita fielmente por varios estudiosos, refiere que los Islamitas, al mando del rey Zepha, asolan Cardeña en el 834; AMADOA DE LOS Rios, en el libro ya mencionado, hace suya la docta opinión de un notable islamista, que justifica el error del monje scriptor al confundir una "zepha"o" zefa", "expedición de otoño" y, por extensión, el ejercito que la emprende. con el nombre del cabecilla. Además, perdona también el "olvido" de una "C" por parte del buen monje. argumentando que en el 834 los vecinos del sur no gozan de buena posición como para cometer tropelías tan al norte, mientras que la fecha del 934 cuadra perfectamente con los paseos militares de Abderramán III, que tanto quebranto causaron a los reinos cristianos. 
La refundación fue benedictina, auspiciada por el propio Conde Fernán González, el disidente que impulsó la conversión del Condado de Castilla en Reino independiente. De esta época datan las estelas visigóticas y los enterramientos altomedievales, antropomorfos y de lajas, aparecidos durante los trabajos de excavación ${ }^{3}$ de la bodega madre del Valdevegón ${ }^{4}$ (hacia 1972) y que ahora están prudentemente guardados en la zona de clausura.

En pleno Medievo, cuatro eran los grandes Monasterios de Burgos: Santo Domingo de Silos, San Pedro de Arlanza, San Salvador de Oña y San Pedro de Cardeña. En 1142, monjes llegados de Cluny pretendieron, sin éxito, imponer su reforma. En horas más bajas (1502) se produjo la anexión a la Casa Grande Castellana, el Monasterio de San Benito de VaIladolid. Antes, había cobrado singular nombre el Scriptorium Caradignense, famoso por el Libro de Morales (914), la Biblia románica y el Cantar del Mío Cid; alcanzó su esplendor en el siglo XI, asociado indisolublemente a las figuras del Abad Sisebuto (+1086) y el propio Ruy Díaz de Vivar (10431099).

A la devoción por los mártires, se añadieron la historia y la leyenda del esforzado mercenario, cuya figura ha venido eclipsando, por la devoción de Corneille en el siglo XVII y de Menéndez Pidal en el pasado, a la no menos señera de Alfonso VI. Aquí encontró aquél, ayuda y refugio en vida, y sepultura a su muerte. ${ }^{5}$

Llegó a Cardeña, como a todas partes, el Decreto de Álvarez Mendizábal, y se vació de monjes entre 1836 y $1942^{6}$. Antes, había padecido la

Trabajos dirigidos por el arquitecto Don Carlos Moliner

Vino riojano de origen y sabiamente criado por los monjes que se puede adquirir en una espléndida tienda regentada por la comunidad cisterciense.

Por desgracia. su sepultura de Cardeña. y la de su mujer doña Jimena, se encuentran vacías, ya que en un rapto de fervoroso patriotismo ambos restos fueron trasladados con toda solemnidad al crucero de la Catedral de Burgos, donde ahora reposan, en un lugar de honor que nunca les correspondio. Quedan en cambio sus descendientes en la liamada Capilla de los Héroes, visitable. en la prolongación del brazo meridional del crucero de la iglesia monástica de Cardena.

Se destinó primero a Casa de Corrección de Monjes. En 1880. por pocos meses, se instaló la "Comunidad errante" de Monjes Trapenses hispano-franceses de la Abadia de Divièlle y en 1888 la "Orden de los Clérigos Regulares Padres de la Madre de Dios de las Escuelas Pias". Ios Escolapios. que sólo se quedaron hasta 1901. En 1905 recalaron en Cardeña los expuisados Frailes Capuchinos de Toulouse. que resistieron alli hasta 1921. Entre 1936 y 1939 le cupo al Monasterio el dudoso honor de convertirse en Campo de Concentracion "experimental", al servicio de ciertas teorias peregrinas del Dr. Valiejo Nágera: algunos supervivientes relataron recientemente con horror sus recuerdos al International Herald Tribune (se puede consultar por Internet: el conocido psiquiatra estaba empeñado en demostrar que los "rojos" estaban atacados por algún tipo de lacra genética). 
visita de las tropas francesas, a cuyas manos sufrió expolio incluso la propia tumba del héroe, ese mismo al que el general Thibault rindió tributo de admiración en 1809 como "Chevalier sans peur et sans reproche".

Tras esta breve aproximación al entorno geográfico e histórico dónde se localizan las recientemente recuperadas pinturas, trataremos de hacer un recorrido por su iconografía y simbolismo, además de detenernos previamente en su estudio técnico, material y formal.

\section{LA POLICROMIA EN LOS ELEMENTOS ARQUITECTÓNICOS. ESTADO DE CONSERVACIÓN INICIAL Y RESTAURACIÓN}

Los trabajos de restauración realizados en la bóveda de la Capilla de los Mártires en el Monasterio burgalés de San Pedro de Cardeña, han permitido recuperar una nueva imagen para tan singular espacio, transformando en escultura, por medio del color recuperado, los elementos arquitectónicos que como tales se conciben y actúan: nervios, plementos y claves.

Cuando se procede a la rehabilitación arquitectónica de las cubiertas en la mencionada capilla y se puede observar de cerca la parte interior de la bóveda, se aprecian fragmentos de color en algunas zonas donde el enlucido se ha ido desprendiendo.

Estos pequeños hallazgos permitieron, a pariir de la realización de una serie de catas sistematizadas y de la toma de muestras para su estudio estratigráfico, documentar la existencia de unas pinturas que si bien son de carácter populai y meramente decorativo, ofrecen una visión del espacio interior de la capilla absolutamente diferente al que presentaba, constituyendo la recuperación de tales pinturas una auténtica sorpresa, máxime si partimos de la base que rige las construcciones benedictinas de la época: la austeridad.

La decoración, cuyo simbolismo e iconografía trataremos de desentrañar a lo largo de los próximos párrafos, consisie en un despiece de sillares delineados con doble trazo en rojo sobre fondo blanco en la parte correspondiente a los plementos de la bóveda y en dragones de un vivo color rojo y grandes fauces abiertas con lenguas serpenteantes en todos y cada uno de los nervios de la doble bóveda. En el punto de unión de seis de esos nervios, una gran clave caireiada en piedra, con un imagen de la Virgen con el Niño, es el punto de partida para el desarrollo de los dragones. Los otros cuatro nervios, tienen como lugar de encuentro un escudo igualmente en piedra y policromado. En él, unas llaves cruzadas en aspa y dos 
manos sujetando sendas palmas de martirio, hacen clara alusión al nombre del Monasterio y a la dedicación de esta capilla. ${ }^{7}$

Resueltos los problemas de filtración de aguas pluviales de la cubierta con la intervención arquitectónica ${ }^{8}$ quedaba dilucidar si persistian las condiciones ambientales propicias a la aparición de humedades de condensación en el intradós de las bóvedas, lo que entrañaría numerosas dificultades para el proceso de restauración de las pinturas y para su posterior conservación, una vez recuperadas, fijadas y puestas en valor.

Para despejar las dudas, con la colaboración de la restauradora del Museo de Burgos, Dña. Adelaida Rodríguez Rodríguez, se depositó en la repisa de una de las claves un sensor autónomo de temperatura y humedad relativa, programado para registrar mediciones cada media hora, entre el 4 de abril y el 4 de mayo de 2002.

Por casualidad, el período elegido coincidió con ciertas celebraciones del Monasterio durante las cuales estuvo funcionando de modo perma-

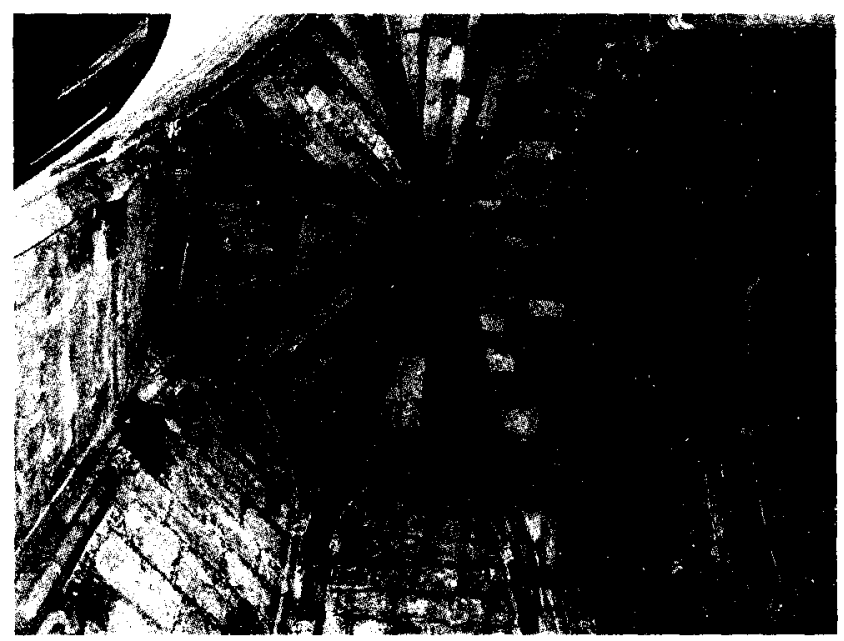

Bóveda de crucería con dragones en los nervios.

Las llaves, que son atributo inequivoco de San Pedro, cruzadas en este caso formando un aspa, junto con las manos que portan las palmas, emblema de los mártires, son el símbolo parlante de los nombres del Monasterio y que más aririba referenciamos.

a Realizada por Construcciones y Restauraciones Ratael Vega S.L., para la Junta de Castilla y León, con proyecto y dirección del arquitecto D. Carlos Moliner López y la arquitecta técnica Dña. Silvia Sáiz Camarero. 
nente la calefacción de la iglesia, de suelo radiante, que por economía no está en marcha habitualmente. Las gráficas resultantes ofrecen una sorprendente estabilidad de parámetros - temperatura casi invariable de $18^{\circ} \mathrm{C}$ y humedad relativa entre el $45 \%$ y el $55 \%$ sin apenas picos bruscos- que para si querrían muchos conservadores en las salas de sus museos. Explicados los resultados por el magnífico comportamiento del sistema de calefacción y los picos de caída de la humedad relativa por las visitas asociadas a la fiesta del 23 de abril en la Comunidad de Castilla y León y al puente del principio de mayo en la Comunidad de Madrid, se demostró además el acierto que suponía haber colocado una gruesa capa de aislamiento entre el forjado y el pavimento del Scriptorium, inmediatamente por encima de las bóvedas de la Capilla de los Mártires. Se había evitado el riesgo de condensación con el aislamiento, pero, además, el funcionamiento continuo de la calefacción había eliminado la humedad excesiva de los nervios, los plementos y sus revestimientos, en la medida justa para poder abordar la recuperación y consolidación de las policromías subyacentes.

Cuando dan comienzo los trabajos de recuperación de las pinturas en el verano del 2002, el estado que presentaba la bóveda era, desde el punto de vista estético y formal, lamentable. Las diferentes capas de enlucidos aplicadas sobre las pinturas a lo largo de siglos y entonces medio dosprendidas y el picado previo que años atrás se realizó en la zona de los plementos para que aquellos agarrasen bien, daba a la bóveda un aspecto desolador (Figs. 1 y 2 ).

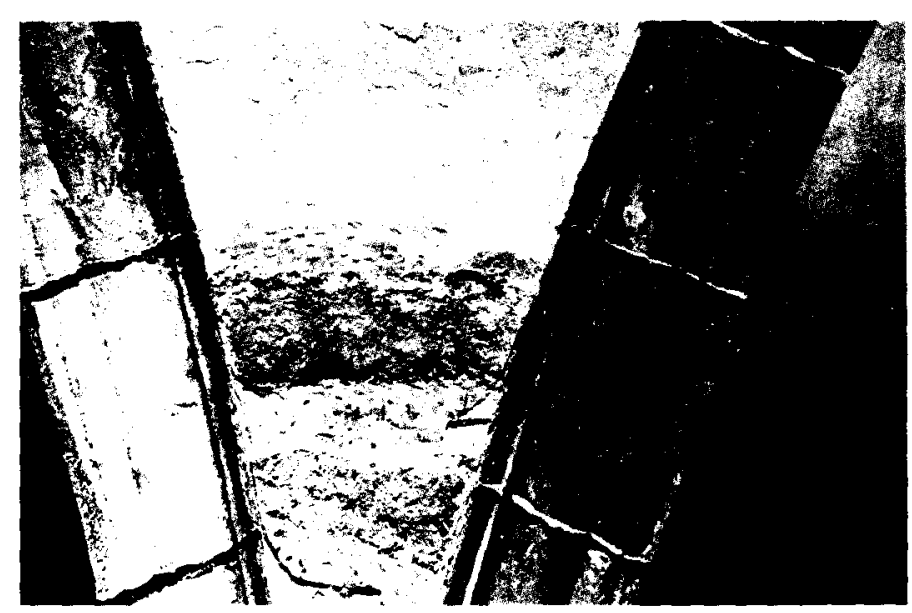

Fig. 1. Enlucidos sobre las pinturas originales. 




Fig. 2. Estado inicial Repintes en la Clave.

Los trabajos de recuperación consistieron, básicamente, en la eliminación de los estratos superpuestos de forma mecánica (desencalado) (Fig. 3); fijación de las diferentes capas de color que estaban pulverulentas mediante aplicación de resinas sintéticas en baja concentración y limpieza del velo blanquecino que permanecía cubriendo las pinturas una vez eliminados el encalado y los yesos.

En algunas zonas de los dragones (cabezas), se detectaron restos de un dorado posterior a la ejecución de las pinturas, seguramente correspondiente a una intervención en el siglo XVIII, momento en el que creemos que también se procede a la aplicación de una veladura a modo de protección ${ }^{9}$ sobre el conjunto de pinturas, que si bien momentáneamente "refresca" éstas avivando los colores, con el paso del tiempo, se convierte en una capa oscura (pardusca o blanquecina) muy endurecida y muy difícil de retirar (Fig. 4).

En la parte de los plementos donde la pintura se había perdido y quedaba a la vista la piedra, ésta, fue consolidada ya que la fuerte humedad (por condensación y filtración) que ha soportado esta capilla, deterioró la

La analítica realizada por el doctor en Químicas D. Enrique Parra, indica que el recubri miento es la tipica pintura de yeso, calcita, arcilla, negro carbon y aceite que se ha aplicado sobre murales y piedras de fachadas desde el siglo xvIII con el fin de proteger éstas. Con el tiempo. dicha capa endurece bastante por la generación de oxalato de calcio, también presente en el re cubrimiento, lo cual dificulta su eliminación. 


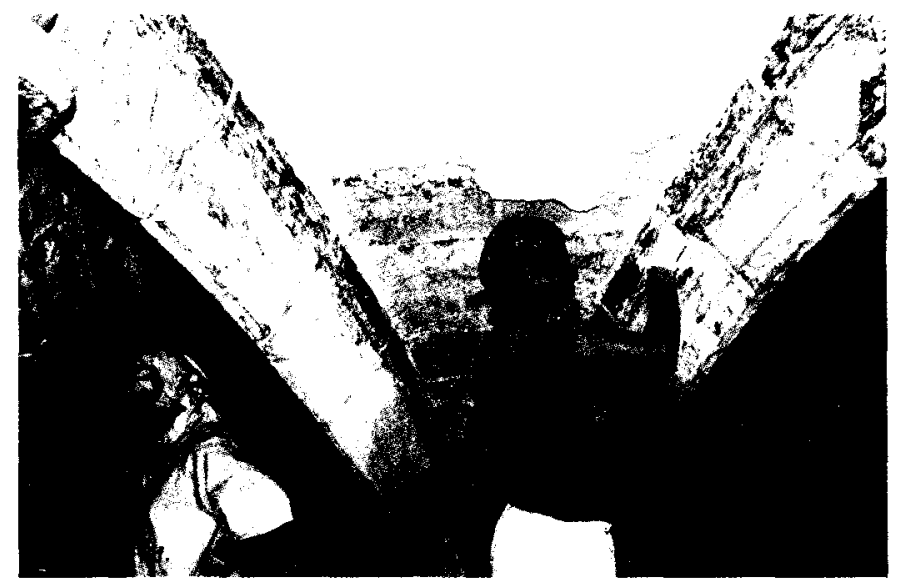

Fig. 3. Eliminación de enlucidos sobre la decoración original.

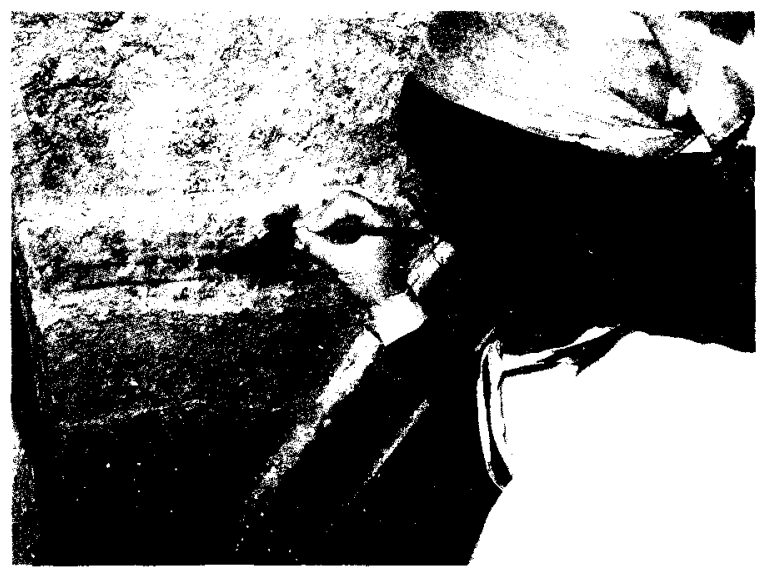

Fig. 4. Limpieza de la superficie pintada en la zona de plementos.

piedra hasta el extremo de suponer la exfoliación de la misma y su desprendimiento en forma, unas veces de lascas y otras tomando el aspecto arenoso característico. La mencionada humedad, junto con la aplicación de la "protección" de siglos pasados arriba mencionada, en cuya composición se ha detectado yeso supuso también la proliferación de sales en superficie que en algunos casos, llegaron a cristalizar. Estas, igualmente fueron eliminadas y tratadas. 
Se sanearon todos los morteros de unión en las juntas de piedra de los nervios, sustituyendo los que estaban sueltos y no eran originales por morteros nuevos. Los restos de despiece de sillar en los plementos eran trozos aislados, por lo que se optó por conservar los mismos y proteger sus bordes, perfilando éstos con mortero que se remató a bisel, evitando así su posible desprendimiento. El mortero empleado, ha sido una preparación a base de cal y arena a la que se añadió una parte de pigmentos en polvo para conseguir una coloración similar a la piedra original y así, favorecer su integración cromática.

Por último, y después de aplicar una mano de resina sintética ${ }^{10}$ a modo de protección de las pinturas, se procedió a la entonación cromática de las lagunas y pérdidas mediante técnica reversible y diferenciable del original.

La clave central de piedra, que estaba sujeta con una horquilla de hierro de doble anilla al igual que la existente en la clave estructural y pasador también en hierro que anclaba ambas, se desmontó para realizar la limpieza de la misma. En este caso, además de la suciedad y las alteraciones que ya hemos señalado para el conjunto de pinturas, había un repinte generalizado a base de tierras ocres que ocultaba el dorado original, realizado al mixtión ${ }^{11}$ en la zona de los caireles y retoques puntuales en el fondo y en la figura de la Virgen con el Niño.

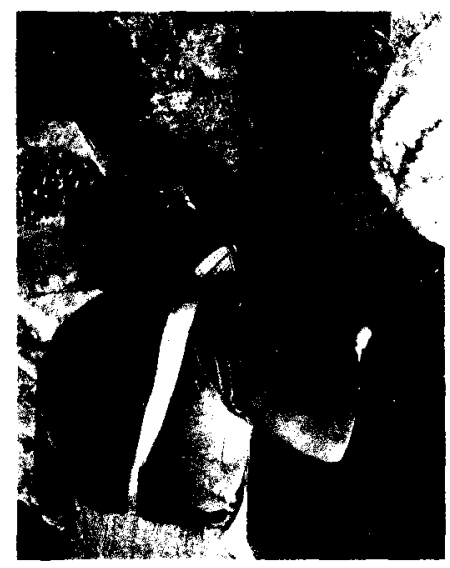

Fig. 5. Aplicación de morteros nuevos.

\footnotetext{
10 Paraloid B-72 al $5 \%$ en Toluero.

Técnica de dorado que permite "pegar" los panes de oro a partir de la aplicación de un
} mordiente. 


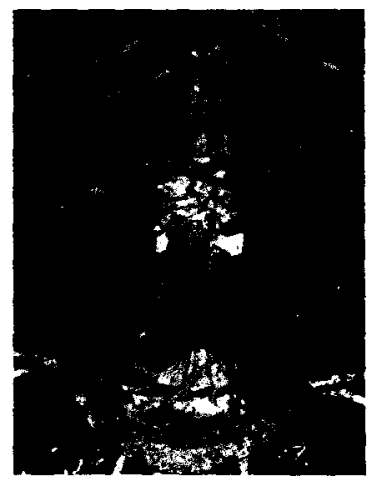

Fig. 6. Eliminación de repintes en la clave.

\section{SIMBOLO Y COLOR}

"Una gran señal apareció en el cielo: una mujer vestida del sol, con la luna bajo sus pies y una corona de doce estrellas sobre su cabeza..." «Entonces apareció en el cielo otra señal: un enorme dragón de color rojo con siete cabezas y diez cuernos y una diadema en cada una de sus siete cabezas. 12

Parece claro que son estos párrafos del Apocalipsis de San Juan los que inspiran la iconografía de la bóveda de la Capilla de los Mártires. La Virgen que preside la clave central de la que parten seis de los dragones, es una clara referencia al texto bíblico, pues como en aquel, está representada de pie sobre una media luna y está tocada con corona ${ }^{13}$ como reina de los cielos. Viste túnica blanca y manto azul con el envés rojo, aunque ese "vestido de sol», que refiere el texto, bien pudiera ser el Niño que lleva en sus brazos, en el sentido que se le ha dado siempre a Jesús de portador de Luz y encarnación misma de ésta. Esta idea, vendría reforzada por el color dorado que bordea el conjunto escultórico ya que el oro corresponde al color místico del sol. El libro abierto que sujeta Jesús entre sus manos es símbolo de sabiduría, enseñanza y autoridad y muestra palpable de los Evangelios que vencerán sobre la encarnación misma del mal que, como veremos representan los dragones.

Apocalipsis, 12, 1; Apocalipsis, 12.3

13. No sólo por su posición en el punto más alto del cuerpo humano. sino por rebasar incluso la altura de la propia cabeza, la corona es símbolo de la superación y es el emblema por excelencia de la gloria, la victoria y la distinción. 
El dragón es el símbolo de la animalidad por antonomasia, mostrando ya un aspecto inicial de su sentido simbólico en relación con la idea sumeria del animal como "adversario", en el mismo concepto que luego se atribuyó al diablo. Cuando el número de cabezas de este «enemigo primordial», "genio maligno" o "demonio", se multiplica, empeora su significación, dando un sentido involutivo y regresivo del aumento numérico. En nuestro caso, tenemos no uno, sino dos dragones, uno con seis cabezas (el que se encuentra bajo los pies de la Virgen) y otro de cuatro cabezas, vencido por el fervor de los mártires de San Pedro de Cardeña.

Cuando la mitología o las religiones acuden a la búsqueda de símbolos para representar el oscuro origen del Universo, el dragón, está allí. Se le considera un ser surgido de las profundidades y el caos de la creación y representa el Mal, en su acepción más amplia.

En la imagen del dragón, hay algo de reptil, hay fauces inmensas, tamaño gigantesco y, en algunos casos, posibilidad de volar. En base a su apariencia, se han propuestos distintos criterios para clasificar los dragones. Uno de ellos en función del medio en el que se mueven: acuáticos, celestes, de tierra y de fuego. Otra posibilidad sería por su forma; así tendriamos dragones alados, dragones serpiente, dragones peces... y finalmente, se podría establecer una tercera clasificación en función del color de su piel o de sus escamas. Hablariamos entonces de dragones rojos, blancos, azules, verdes, dorados.... Aunque quizá, la principal clasificación, se establece entre posibles "razas" de dragones, diferenciando entre los dragones parecidos a serpientes (nuestro caso) y aquellos otros dotados de alas. La asimilación del dragón con la serpiente, nos aproxima al mito del dragón originario principio de la Creación que comienza por crearse a sí mismo, igual que la serpiente renace cada vez que cambia la piel.

Los bizantinos, herederos de los romanos en muchos aspectos, crearon una simbología propia para el dragón: lo consideraron símbolo del caos, las calamidades públicas como la enfermedad o el hambre y por ello, lo representaron siendo vencido por el centurión. Evidentemente el cristianismo toma todos estos símbolos y los adapta para las enseñanzas de sus fieles. Los artista medievales, se encargan de plasmar mil y un dragones en las gárgolas de las catedrales, en los capiteles de los claustros, en los Bestiarios, Libros de Horas y Beatos... Todo esto sin olvidar, la multitud de referencias a este animal fantástico que encontramos ya en el Antiguo Testamento: “... al cachorro de león al dragón hollarás..." (Salmo 91:13); ".... haré de Jerusalén un montón de ruinas, una guarida de dragones...." (Jeremias 9:11). 


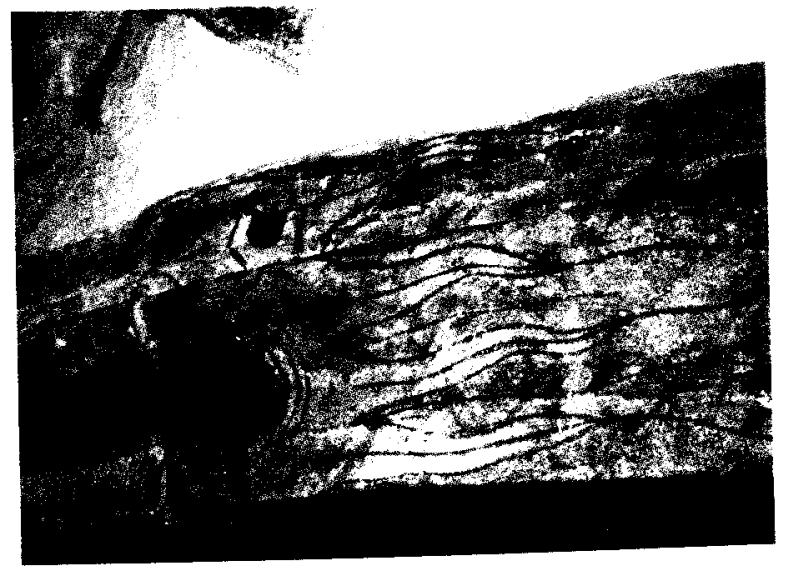

El color tiene también un eminente significado religioso y por tanto, la elección de los colores para cada una de las formas representadas no es algo aleatorio. La policromía guarda una estrecha relación con las figuras que decora, contribuyendo a reafirmar el simbolismo de éstas y pudiendo ser cada uno de los colores, referencia identificativa de ciertas representaciones.

En la tradición cristiana, el color no es otra cosa que la participación de la luz; el Verbo de Dios es llamado "luz procedente de la luz». La interpretación de los colores sigue, en las representaciones cristianas, las normas de la antigüedad estableciendo para cada gama de colores un significado particular, que inmediatamente se asocia con un determinado contenido. Fueron los prelados y los teólogos quienes registraron todos los códigos y sistemas cromáticos, construyendo en torno a los colores, sistemas de valores precisos, con una repercusión enorme sobre los demás métodos de representación. El poder pedagógico de la imagen como captadora de los sentidos es evidente y por ello se utiliza para despertar en el fiel (espectador) el fervor religioso.

Aunque la belleza como tal es admitida como eficaz en las representaciones plásticas, estas no siempre se miden por su valor artístico o estético. sino por el contenido y significación espiritual que formas y colores encierran en sí mismos. Así pues, las imágenes pintadas, son el claro reflejo de la codificación a la que estuvo sometido el color en las sociedades pasadas.

Si tenemos en cuenta que la colorida decoración de esta bóveda se inscribe en el capítulo de una fundación creada bajo las enseñanzas de 
San Bernardo, y que éste abad de claraval encarnaba la tendencia decididamente cromófoba de la orden cisterciense, este fogonazo de color en la capilla, es aún más sorprendente si cabe ${ }^{14}$.

El color rojo, con una gran carga simbólica tanto en el mundo pagano como en el cristiano, posee una dualidad conceptual vinculada por un lado con la idea del fuego y por otro con la idea de la sangre. Este color, puede tomar un significado positivo o negativo dependiendo del contexto. Así, en la bóveda, el rojo de los dragones, no viene sino a reforzar el sentido maligno de estos, ya que del rojo sangre, el Cristianismo medieval hace surgir el rojo del pecado, el rojo infernal. Según J. Chevalier y A. Gheerbrant, en su libro "Diccionario de los símbolos", la ambivalencia del color rojo (de la cual proviene buena parte de la fascinación que produce esta tonalidad), tiene un valor arquetípico que se relaciona con el de la serpiente. El amarillo seleccionado para pintar las cabezas, representa la falsedad, los celos, la avaricia, la envidia, la traición. El negro con el que se delinean las grandes fauces y dientes del dragón, el ojo que trata de vigilar todo a su alrededor y las escamas que discurren por el cuerpo, es simbolo de la nada, la negación de la luz, la negación, por tanto de la divinidad. En este sentido, no cabria representar a este ser, dragón/serpiente, con otros colores.

Por otra parte, el rojo es también el color que se utiliza en el envés del manto de María, así como para delinear los sillares de los plementos. En este otro contexto, -en la figura de María-, simboliza todos los valores positivos: valor, coraje, caridad, fuerza. En el mundo esotérico (no hay que olvidar que el simbolismo cristiano de los colores es herencia de todo lo anterior) el rojo es el color del alma y del corazón; de la ciencia y del conocimiento, color prohibido a los "no iniciados". Los tres colores de los vestidos de la Virgen, _-rojo, blanco y azul-, representarían, pues la ciencia secreta.

Según la Dra. Alicia Sánchez Ortiz ${ }^{15}$, en la tabla que hace del simbolismo que tienen los colores en las representaciones cristianas a finales de la Edad Media, el azu/ representa lealtad, justicia, sabiduría, amor fiel; y el blanco riqueza, nobleza y fe, virtudes todas ellas atribuidas a la Virgen y utilizadas en la policromía de sus vestidos en la clave.

14 Para luchar contra la seducción sensible de la naturaleza en aquellos que no refieren sus bellezas directamente a Dios, San Bernardo recomienda la grisalla en la arquitectura cisterciense; un capítulo de su orden exige que las letras historiadas no sean más que de un color y sin florituras.

15 "Sistemas simbólicos y códigos cromáticos en la lconografia Cristiana" Curso de verano, julio 2002. Inst. Universitario de Restauración. Universidad de Burgos. 



Clave central con Maria venciendo sobre los dragones. 
Todas estas virtudes, encarnadas en Maria y su Hijo, son las que harán que venza el bien, la verdad y la luz sobre el maligno dragón. Los santos mártires de San Pedro de Cardeña, con la protección de la Virgen y representados en el escudo vencerán también sobre el pecado y las tinieblas, sirviendo de ejemplo para los fieles.

La iconografía de esta bóveda gira pues, en cuanto a su representación formal y el significado simbólico de su policromía en torno a la alegoría del triunfo de la doctrina cristina sobre el mal y el pecado que encarnan los dragones rojos.

\section{BIBLIOGRAFIA}

Perez-RIoja. J. A.: Diccionario de simbolos y mitos (Ed. Tecnos, 1984).

CIRLOC, J. E.: Diccionario de simbolos (Ed. Labor, 1984).

Chevalier, J.Gheerbrant, A.: Diccionario de los simbolos (Ed. Herder, 1986).

Charbonneau-Lassay, L.: El Bestiario de Cristo. El simbolismo animal en la Antigüedad y la Edad Media (Ed. Liberdublex, S.L., 1996).

El fisiólogo. Bestiario Medieval (Ed. Obelisco, S.L., 2000).

Duchet-Suchaux, G./Pastoureau, M.: La Biblia y los santos (Alianza Editorial, S.A., 1999).

Ferrer Morales, A.: La Pintura Mural, su soporte, conservación, restauración y las técnicas mo dernas (Ed. Univ. De Sevilla, secretariado de publicaciones, 1995).

Centron, E: Mundo Politico y expresión poética-Cantar de Mio Cid (1974, Montevideo).

SMITH. C.: Poema de Mio Cid (1972, Oxford).

DYVER, N. J.: El Mío Cid del taller alfonsi (1995, USA).

Espalza, M. DE y Guellouz, S.: Le Cid. Personnage Historique et literaire (Islam d'hier et d'aujord hui). (1983. París).

Gariano, C.: Lo religioso y lo fantástico en el "Poema de Mio Cid" (1964. Washington).

Menendez Pidal, R.: Cantar de Mío Cid, Vol. I y II. Critica del texto y gramática (1954. Madrid). 